\title{
INTEGRATING HUMAN-CENTERED DESIGN METHODS IN EARLY DESIGN STAGE: USING INTERACTIVE ARCHITECTURE AS A TOOL
}

\author{
Zeyad M. El Sayad, Tarek Farghaly and Sara Mohamed Hamada \\ Department of Architecture, Faculty of Engineering, Alexandria University, Egypt
}

\begin{abstract}
During the early-1980s the term Human-centered design (HCD) evolved and since then it started to achieve a rapidly-growing attention. It is considered to be a user-incorporated design and development process. This is achieved by primarily understanding the users' needs in buildings, communities, services, systems and products. HCD methods aim to achieve an ideal space emerging using the human centered interaction scheme. Interactive Architecture is thought to have a great potential in achieving HCD benefits. Therefore, this paper discusses the phenomenon of Interactive Architecture as well as defining the behavior of the human body in order to document and examine the buildings. The research's main aim is to incorporate the phases of the Human-centered design into the early design stage of architectural buildings using Interactive Architecture. The methodology is composed initially of a literature survey discussing the Human-centered design in general and then focusing on the methods of creating an Interactive building space. This is then followed by analyzing both aspects in relevant examples. Finally, a matrix is concluded reaching the optimum guideline methods of design in architecture, through integrating HCD methods with Interactive Architecture analyzed examples.
\end{abstract}

\section{Keywords: Human-Centered Design; Interactive Architecture; Interactive Building Space; Body In Space.}

\section{Introduction}

Human-centered design is a term used to describe the integration of end users within a design process. HCD was growing under the human centered interaction technique, which started with technological and product system industries leading to Interactive Architecture. The development of computers and telecommunication has been changing the personal life of humans since the 1990's through making distances unconnected. Since then, human aspects have been affected physically due to the collaboration between the computer's capabilities and the real world [1]. Consequently, buildings use technology and accommodate expertise and therefore buildings, as objects, become intelligent and interactive. This paper is concerned with the study of human bodies and spaces individually and with the relation between them. This leads to the ideology of incorporating the performance of the human

bodies in the design process of a building. Rethinking efforts should therefore be employed in the design [2]. As a result, a new architectural trend has developed addressing the communal needs to have dynamic spaces. This could be achieved using digital technologies, on the basis of information processing and integration among the design performance and maintenance processes. Hence, these progresses lead to Interactive Architecture that can interact with the built environment using the HCD approaches. 


\section{Literature review on Human-centered design}

\subsection{Definition of human-centered design}

Following the growth of the field of environmental psychology in the 1970's, a new term originated in the early 1980's by the late Ronald Mace, called "universal design" or "Humancentered design" [3]. Many terms were then used to refer to HCD such as "people-centered design", "user-centered design (UCD)" and 'person-centered design'. HCD was frequently misjudged and rumored to be a design style. Therefore, HCD could be defined as a process for designing and developing everything for humans who will use them, such as buildings, communities, services and products, regardless of age or ability [4]. In other words, the design is based on the physical and psychological needs of the human users, including all aspects of the physical environment, in order to meet the needs and abilities of the users by enabling them to highly function [5].

\subsection{Human needs}

"Human needs" model was deliberated by Abraham Maslow which defines human needs in a five level pyramid, sorting needs in sequence from bottom to top [6]. It starts with the physiological needs followed by the safety needs. Then comes the social needs, and esteem needs, which are also known as deficiency needs (D-Needs). The final top level is selfactualization which demonstrates the growth needs (G-Needs) and is divided into four parts (cognitive needs, aesthetic needs, self-actualization and self-transcendence) [] []]. The model was developed forming a new conceptual model.

\subsubsection{Using the conceptual model of human-centered design}

A conceptual model is developed by collaborating Maslow's model [ 6$]$ (micro and psychological angle) and Küthe's model (macro and social angle) with the new model adopted by IDEO (international design and consulting firm). This includes useful, usable, and desirable (see Figure 1) []ㅡ.

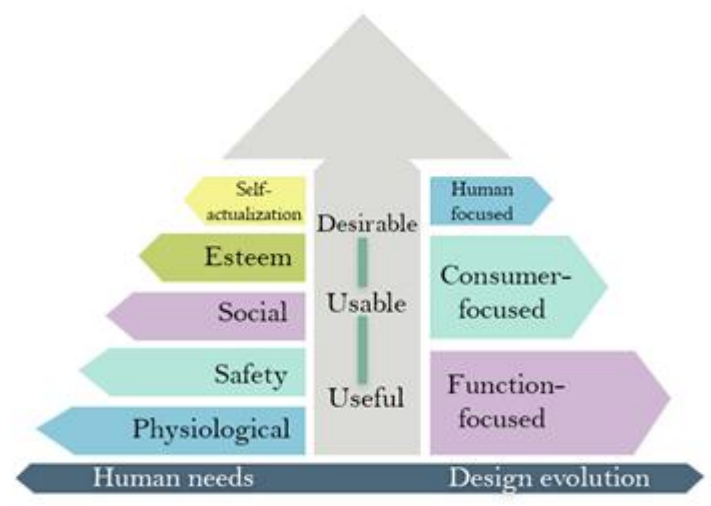

Figure 1: A conceptual model of human-centered design.

Source: Ting Zhang and Hua Dong, 2008, Human-centered design: an emergent conceptual model.

\subsection{Developing human-centered design cycle}

There are five processes for the human-centered design cycle in order to meet usability requirements according to the ISO standard (see Figure 2) [9].

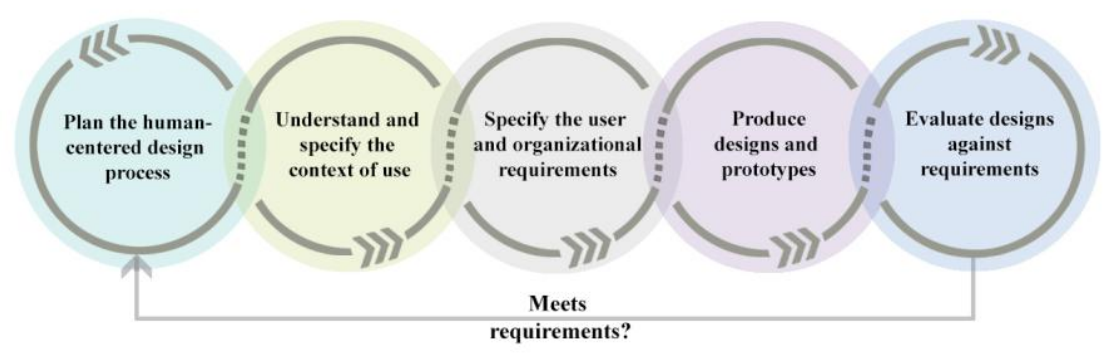

Figure 2: Diagram of human-centered design cycle.

Source: ISO, 1999, Human-centered Design Processes for Interactive Systems. 


\subsection{Human-centered design process}

With the ongoing development in this field, many problems arouse that led the designers to construct a certain process in order to find effective solutions. The designers' deep understanding for the communities and users' demands helped them in finding new solutions, which in turn helped the building and testing ideas before putting them out into the world [10]. The HCD process varies between tangible and intangible ways of thinking through the three phases (inspiration, ideation and implementation). Inspiration is where the designers have to understand people, notice their lives, and hear their hopes and desires. Ideation means that designers have to make use of everything heard from people, come up with many ideas, and examine solutions. Implantation indicates that the designers have to apply ideas in a way to maximize its benefit to the world.

\section{Human-centered design in Architecture \\ 3.1. Developing features of human-centered design guidelines}

HCD guidelines help architects and designers in the vital process of realization of the user's visions and formulation as an approach for knowing the potential of a place. HCD guidelines aren't just a tool for architects and it's not another word for design standards [11]. The standards begin with principles that suggest that learning happens in a restricted set of ways supported by limited space configurations. Some features are going to be discussed to reach the ideal guideline of HCD methods in architecture.

\subsubsection{Providing colors, lightings and acoustics in spaces}

Colors have a certain implication on the behavior and the state of mind when used in the design of environments which rather influences the user's emotional and mental balance [12]. As a result, colors can be used as a tool in solving numerous design problems; if it is used to fully utilize, it will offer many influences to the built environment [13].

In addition, Lighting affects the quality of the personal experience within a space (Halletal, 2001). Hence, people see space according to the way light integrates within the space. Architecturally, it is essential to include the object and the viewer in the process of situating the lighting of a space. It can then be analyzed as color, space or material. A famous architect Le Corbusier stated that: "Architecture is the skillful, accurate and magnificent plays of volumes seen in light." [14]

Accordingly, various external and internal factors have an effect on the noise of a space such as finishes, traffic, and ventilation system (Ecophon, 2002). Therefore, good acoustic environment regulators' are required to control the noise of a space and minimize the undesirable impacts on the activities taking place inside the building. In the Architectural design process, acoustics in HCD have four aspects to be considered: sound isolation; building services noise; vibration control, and room acoustics. As a result, in order to design a building that achieves beneficial acoustics, a suitable echo pattern must be taken into account as it is considered important in several buildings.

\subsubsection{Healthful}

Recently, a combination between ergonomic principles, environmental principles and the sustainable physical well-being is present in health spaces. It is attained through ergonomic considerations, lighting, color, and sound.

\subsubsection{Stimulating}

People are attracted by stimulating spaces to generate creative thinking, motivation and engagement. Six stimulations originated including: sensory cues, surprising elements, transparency and visual access, connection to nature, color and texture, and diverse shapes.

\subsubsection{Balancing community and solitude}

Public spaces should balance between human needs for community and solitude. Moreover, buildings should offer a balance between interactive and private spaces [11]. 


\subsubsection{Adaptable}

Variation, activities and people are supported by adaptable spaces. Building environments need to be adapted to the everyday changing activities. Adaptable spaces are classified into: flexible space, adequate space, welcoming and familiar space, user ownership, changeable focal points, mobile displays, diverse information communication, and technology tools.

The previously reviewed features of the HCD guidelines in architecture led to a description of HCD levels in architecture that will further be discussed in order to reach the optimum design methods of architecture.

\subsection{Integrating human-centered design levels in architecture}

Human-centered design levels are classified according to its use. The main form of most levels depend on people's needs such as psychophysical, psychological, cognitive, emotional, anthropometric, biomechanical, and sociological data and models. Thus, several HCD levels contain verbal and non-verbal means that act as alternatives to techniques and methodologies for interacting with people to help reveal the meanings, desires and needs [1]. Some examples of $\mathrm{HCD}$ in architecture include:

- Lever door handles: used by children and old people with weak wrist strength;

- Zero-step entryways: into a home or building, it helps people who cannot get across the steps properly from falling for all ages including children, old people, and wheelchair users.

- Interior-environment features: through making a raised-height step for dishwashers, dryers, and clothes' washers inside the kitchen space that must include a sit work space.

- Exterior-environment features: Including covered bus stations with benches for people; sidewalks; complete streets to allow easier and safer passing, and no-slip driveways.

- Walkable communities: in which the design connects places of employment, residences and commercial areas by designing bikeways, pathways, and sidewalks to help residents move easily and safely without using cars [15].

\subsection{Involving the human-centered design guiding principles}

The designers have to address the human needs, values, beliefs, motivations and limitations according to the way people think, behave and feel, putting into consideration their culture and social standards. Therefore, expressive buildings, products, systems and services are important for a designer to impress people. As a result, architects must put into consideration people's comfort, releasing their brains and bodies for learning [11] by knowing the brain mind learning principles.

\section{Using methods of Human-centered design}

In 2008, new methods were developed and arranged to involve people in one or more possible features, providing chances for social investigation of buildings [16]. However, Table 1 lists HCD methods, which are commonly arranged by human-centered designers, which are used in Interactive Architecture [17].

After understanding the use of each method in its field, it is concluded that in order to reach the ideal new guideline methods of design in architecture, integration must be done between HCD methods and interactive applications in buildings. Correspondingly, Interactive Architecture is chosen as a focus of the study as it utilizes digital technologies of quantitative and qualitative performance-based simulation to offer a comprehensive new approach to the design of the built environment. 
Table 1: A list of methods arranged by human-centered designers. (Derived from Giacomin J., 2014, what is human centered design?)

Facts Regarding Humans and Society:

\section{- Anthropometric data sets and models - Biomechanical data sets and models - Psychophysical data sets and models - Cognitive data sets and models}

- Emotional data sets and models - Psychological data sets and models - Sociological data sets and models - Philosophical data sets and models
Capture of Meanings and Needs (Verbally based):

- Ethnographic

interviews

- Questionnaires

- Day-in-the-life analysis

- Activity analysis

- Cognitive task analysis

- The five whys

- Conceptual

landscape

- Think aloud

analysis

- Metaphor elicitation

- Be your customer

- Customer journey

- Personas

- Scenarios

- Extreme Users
Capture of Meanings

and Needs (Non

Verbally based):

- Game playing

- Cultural Probes

- Visual journals

- Error analysis

- Fly-on-the-wall

observation

- Customer Shadowing

- Body language

analysis

- Facial coding

analysis

- Physiological

measures

Electroencephalograms
Simulation of

Possible Futures:

$$
\begin{aligned}
& \text { - Word concept } \\
& \text { association } \\
& \text { - Role playing } \\
& \text { - Focus groups } \\
& \text { - Co-design } \\
& \text { - Experience } \\
& \text { prototype } \\
& \text { - Real fictions } \\
& \text { - Para-functional } \\
& \text { prototypes }
\end{aligned}
$$

\section{Interactive Architecture}

During the $21^{\mathrm{st}}$ century, many technological changes took place causing transformations in many industries and trades. Using these technologies, architects became able to create interactive spaces that are designed to initiate movement and interaction within the space. Thus, the occurrence of the integration of digital media and technology in architecture help support interaction and exchange cohesion and communication [18]. Interactive Architecture (IA) can interact with the environments like an alive object by using the HCD methods (see Figure 3).

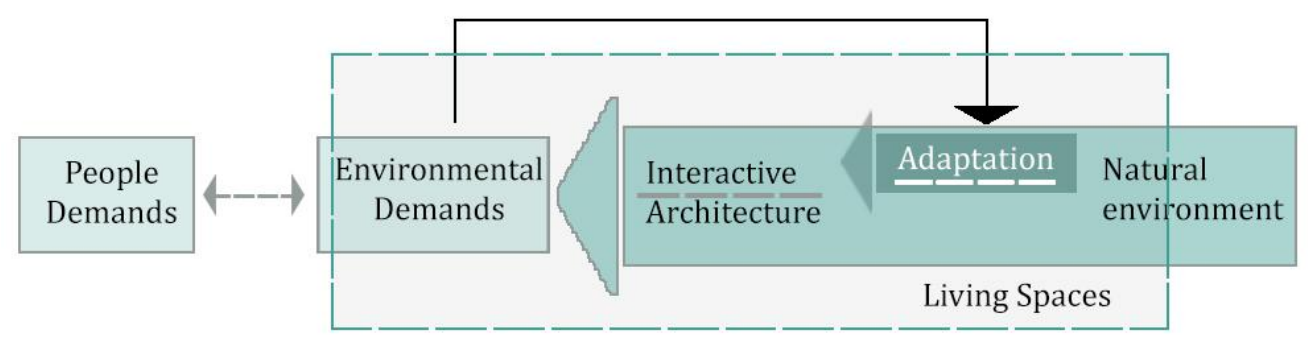

Figure 3: How Interactive Architecture can respond to environmental and user demands Source: The Author

\subsection{Definition of Interactive Architecture}

Interactive Architecture has been defined by Michael Fox and Miles Kemp, such as: "A vision for the future through contextualizing and understanding the current landscape of projects and trends in IA, and its integration of new emerging technologies. The current landscape of interactive space is built upon the convergence of embedded computation (intelligence) and a physical counterpart (kinetics). That satisfies adaptation within the contextual framework of human and environmental interaction" [19]. 


\subsection{The concept of interactive space}

Space and modes can be transformed through digital technology, to recognize the changing needs and desires. Two main challenges face architecture: the need to merge performs and images of a digital culture with materiality; and using digital technology to change the limitations of the built environment [20]. Thus, designing a dynamic 'interactive space' is made through universal computing, which is used as a tool to emphasize the interactive media and network technologies.

Accordingly, specific properties of such spaces were mentioned by McCullough through some technical issues: (1) Participative: support multi-user participation for richer experience. (2) Transformative: Open systems for places able to change and must be spontaneous and learning, not load the user with the technology. (3) User-centric: physically put and support user's intentions, actions and manners [21]. The interaction with computer systems was named "embodied interaction" by Dourish (2004) who suggested three common elements to reach a successful embodied interaction [22]:

- Participative: Embodiment is a participative status, a way of being, rather than a physical property.

- Task accomplishing: Embodiment directed towards the achievement of practical tasks.

- Practical Action: Embodiment as a source for intentionality, rather than as the object itself.

\subsection{Classification towards Interactive Architecture}

Interactive architectural spaces are categorized by integrating HCD methods and applications into a suggested classification (see Figure 4). The classification is proposed to accommodate basic types; (Type- A), where the whole building interacts with the users and responses; (Type- B), where art installations were added in an architectural space to interact with the users. Four sub-categories are further discussed in (Type-B):

- (B1): Interactive floors; works on converting kinetic energy made by humans' dance, walk or jump into electrical energy.

- (B2): Interactive Interior spheres and walls; an art installation interacts with individual users within a space through a wall or sphere .

- (B3): Interactive interior envelope skin; where the interaction is made in an interior skin within a building/space through the movement of users or breather in space.

- (B4): Interactive landscape; fixing elements in the landscape which interact with the user's motion or sound.

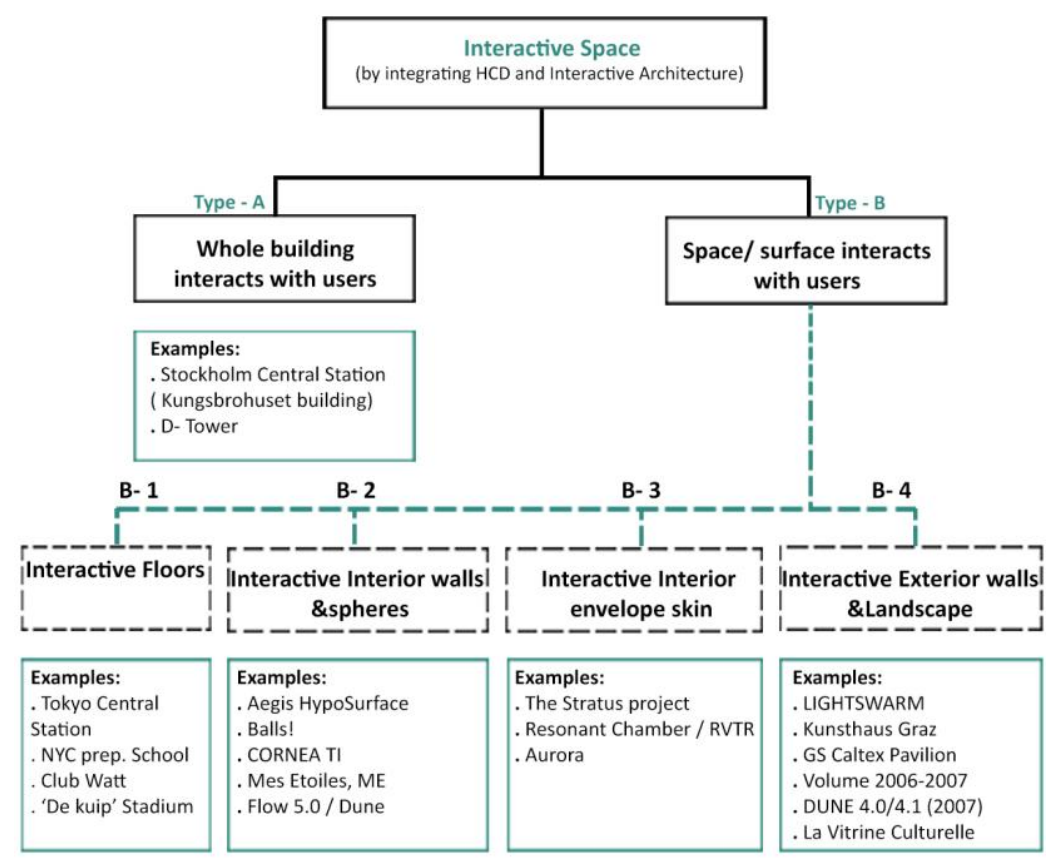

Figure 4: Suggested classifications from the examples. Source: The Author 
The theoretical background of the concepts of HCD and Interactive Architecture and their principles was previously discussed. Thus, the paper will analyze a selection of projects that refer to these concepts, and illustrate the characteristics of these projects as a result of analysis.

\section{Analysis of Examples of Interactive Architecture using Human-centered design methods}

Human's body is the source of orienting people within a space, locating them and giving them a point of origin with which to understand the world. Christopher Day stated that: "We experience buildings not as objects but as boundaries of space" [23].

\subsection{Type-A: Whole building interacts with users}

\section{- Stockholm Central Station-Turning Body Heat to warm buildings (Kungsbrohuset Building)}

A Swedish company decided to use the wasted energy to reduce energy costs, which was considered an abnormal energy source. The station is regarded a warm space, due to the presence of numerous shops and restaurants, in addition to the huge number of visitors, which is believed to be around 250,000 persons per day. In order to generate energy from body heat, the process begins from the persons in the station, which is able to heat a building separated from the station [24]. This urged the architects and engineers to find an effective method to use the body heat and transfer it to be used in a new renovated office building called Kungsbrohuset located next to the Stockholm central station (see Figure 5).

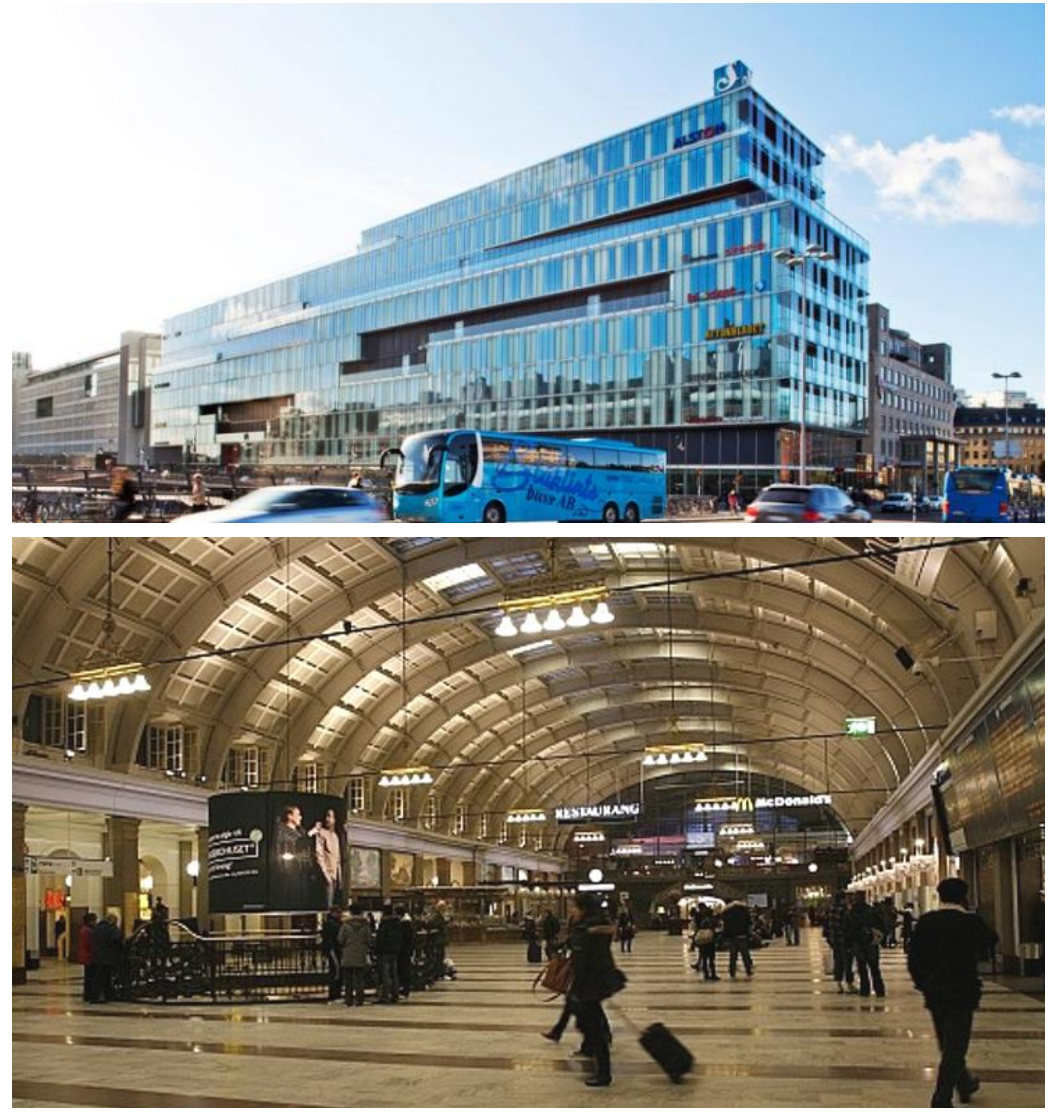

Figure 5: Stockholm Central Station interior shot on the left and Kungsbrohuset the environmentally friendly building on the right

Source: Tara Kelly, 2010, Body Heat: Sweden's New Green Energy Source and Williams, 2012

The system: the excess heat generated by visitors in the Stockholm Central Station can be transformed to hot water and pumped to the other office building in order to be transformed to basic heating in the offices by using standard heat exchangers in the ventilation system.

Observation: the interaction between users' performance and the building is highly achieved through harvesting body heat and transferring it to heat a building, which is done by using 
technology with the human's body. Thus, the significance of using HCD methods with the Interactive Architecture is essential.

6.2. Type-B: Space/Surface interacts with users

- Interactive Floors (B1): Energy-Generating Floor tiles make US Debut at NYC Prep School

Interactive floor tiles' function is to generate energy from the daily human activities like walking, jumping, dancing, running, etc. The footfall energy harvesting floor operates by converting kinetic energy into electrical energy [25]. Thus, twenty four tiles of energy generating floors covered 12 meters of the Simon's Langton Grammar School for Boys in Kent corridor (see Figure 6), to covert the student's kinetic energy derived from the pressure of walking and running into a sustainable energy source.
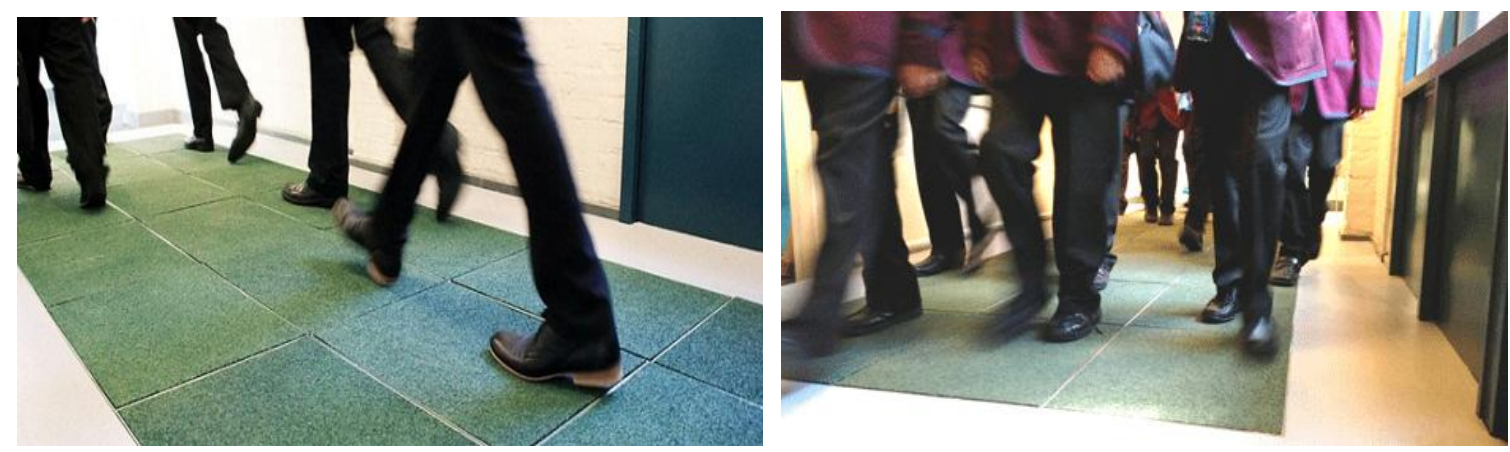

Figure 6: Interactive floor tiles underfoot at the Simon Langton Grammar School for Boys in Kent. Source: Pavegen, 2014

The system: It is made up of a sequence of meshing tiles made from networked sensor tiles, each of which has around a dozen of small pressure sensors connected to a fixed computer. The processors on all tiles are networked when the tiles are snapped together.

Observation: using sensing technology is not only used to detect movement, but also transforms that movement into electricity. This results in a mutually beneficial relationship between the user and the interactive floor, where more movement results in more electricity.

\section{- Interactive Interior walls and spheres (B2): BALLS!}

Ruairi Glynn and Alma-nac Collaborative Architects designed BALLS! application for Arup's Headquarters in London [26]. The design of BALLS! converts the atrium of the engineering firm Arup's headquarters in a spectacular way, and additionally communicates a number of unseen data sets within the whole building, including the number of workers, energy consumption, noise from meeting rooms, intensity of internet traffic, and quantity of coffee consumed.

The system: BALLS! application consists of spheres which change in color by rising and falling, giving real-time data sets about any movement or any number of phenomena happening in the building (see Figure 7) [27].

Source: Michael Fox, 2016, Interactive Architecture: adaptive world. 

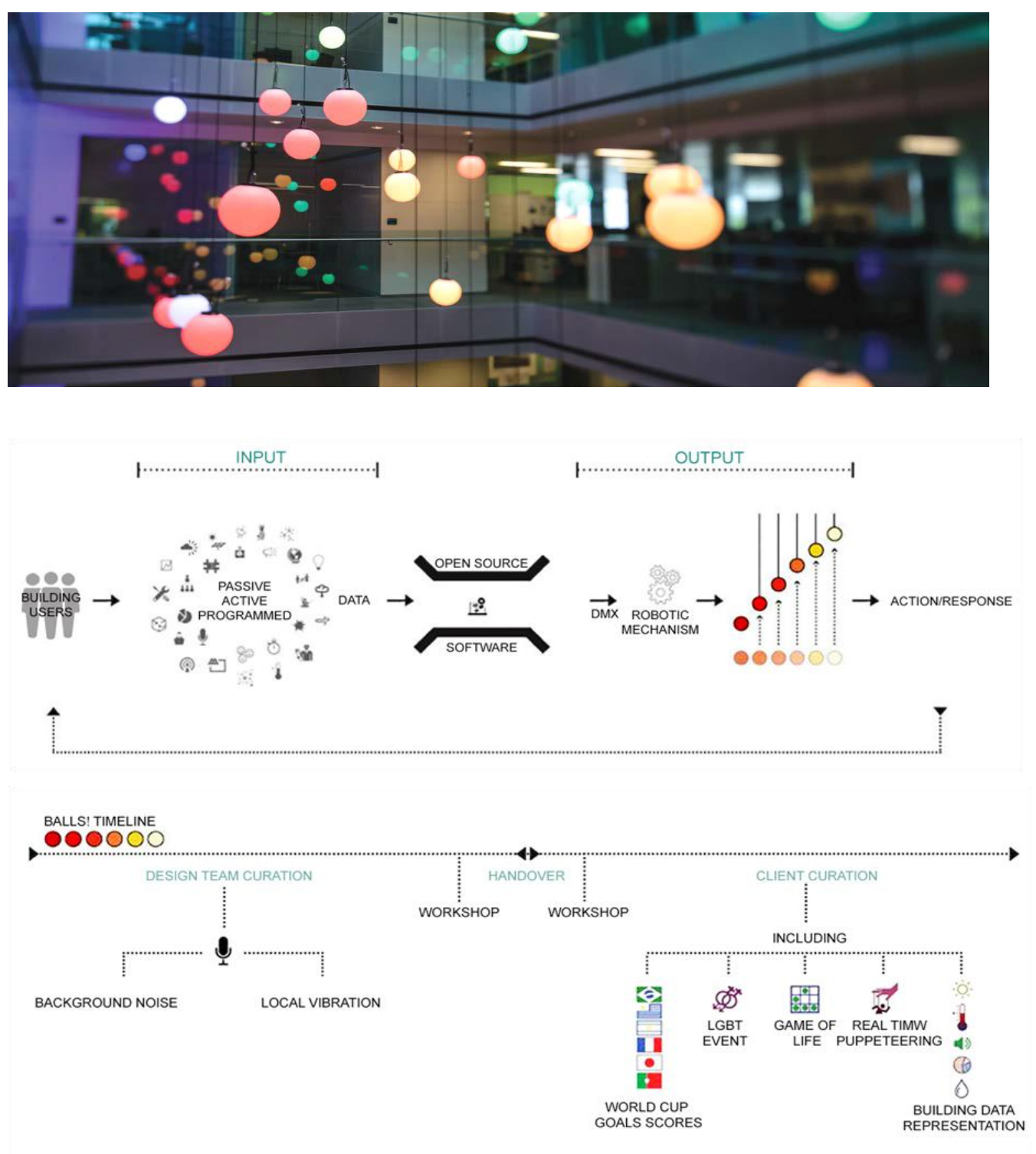

Figure 7: Conceptual diagrams of interaction.

Observation: the concept of the interactive balls with humans is used through the human performance, sensors, microphones, and LED coloring lights. Therefore, it creates a platform for social interaction as users are encouraged to move in various directions in the atrium platform to render in different lights. Thus, Interactive Architecture is used through taking human performance into consideration by using human-centered design.

\section{- Interactive Interior Envelope skin (B3): The Stratus project}

The Stratus Project arouses the human's attention to the soft systems of architecture such as air quality, thermal gradients, acoustics, and light. This helped in making prototype envelopes that improve continual information and material exchange, and interchange between inhabitants and atmosphere. The main goal of the project is to clarify the conditions of interior ventilation, in addition to the occupant's effect on those conditions; and to improve the environmentally interactive elements of architecture [28].

System: the Stratus project is a system of layers that cover a raised floor installation housing displacement ventilation and piezoelectric energy harvesting, to a kinetic building offering dispersed and modified spatial and environmental adaptability (see Figure 8). The volume of space is changed due to inhabitance through the general movement of the ceiling [29]. 

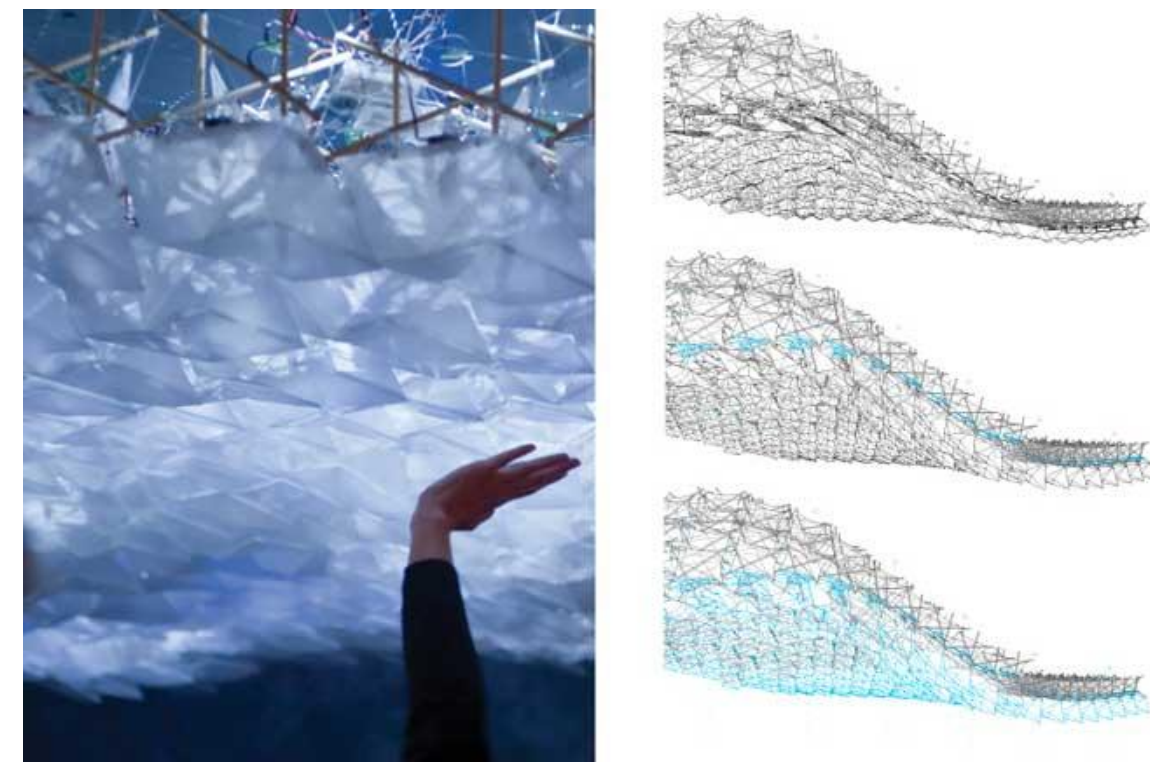

Figure 8: The section showing undulating surface and deployment of breathing cells relative to sensed temperature fluctuation.

Source: RVTR, 2012

Observation: the Stratus Project designed an integrated interior interface and responsive interior skin to be locally adjusted, and might be an extension of the individual body and their atmospheric scope. This is achieved using the visitors' breathing to communicate and to be reflected on the atmosphere's responses within the skin, and improve the environmentally interactive elements of architecture.

\section{- Interactive Exterior walls and Landscape (B4): DUNE 4.0/4.1}

Two types of Dune were developed by Daan Roosegaarde; Dune 4.0 is located in the main corridor of Montevideo in (Amsterdam, NL), while Dune 4.1 is located in the Maas tunnel for the Rotterdam 2007 City of Architecture [30]. The main concept is to mix nature and technology functions as a platform, to improve the relation between the existing architecture and the visitors, and to develop a new layer of architecture, by merging its intelligent qualities with the human body. The space and visitors are merged by walking, looking and interacting with the Dune [30].

System: It consists of hundreds of fibers (see Figure 9) that contain software that changes itself dynamically, by ignoring the continuous noise made by a ventilator which is realized by the software. The installation always stays fresh for new input of the visitor. The output is established $70 \%$ on the motion and $30 \%$ on the sounds of the visitors [31].
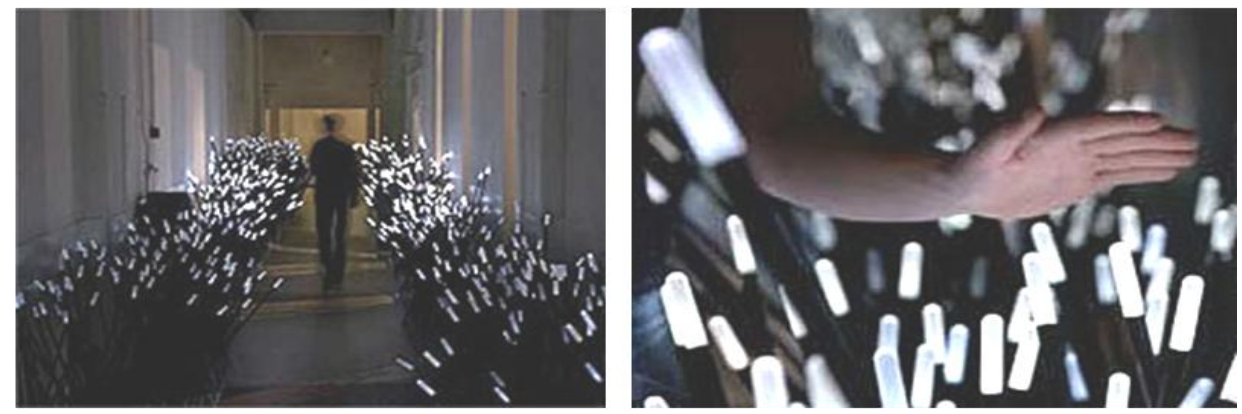

Figure 9: Interaction of human with the dune project in corridors. Source: Ruairi Glynn, 2007.

Observation: this kind of interactive technology uses HCD methods to create an installation that engages the users with their sense of sound and touch. The sensory technology used in Dune 4.0 and 4.1 can be used in the building's design, where sensory technology will be used to emit sounds and lights within the architectural space. 


\section{Common design characteristics}

The integration between Interactive Architecture and interaction within the design resulted from merging subject matters and increasing social values, leading to the development of the human's interaction by handling, formation, and sharing meanings. Three components are defined by a well-known scientist, as the basis for embodied environment such as task accomplishing, practical action, and participation [22]. More characteristics are recognized from the examples, which are clarified in Table 2.

This paper discussed 5 projects, each demonstrating a different type of interaction. To conclude, the following checklist in table 2 illustrates the evaluation of the characteristics of Interactive Architecture in the reviewed examples: Stockholm Central Station, NYC prep. School, BALLS!, The Stratus project, and Dune4.0/4.1.

Table 2: Matrix of the common design characteristics institute, (The Author).

\begin{tabular}{|c|c|c|c|c|c|c|}
\hline & \multirow{3}{*}{ 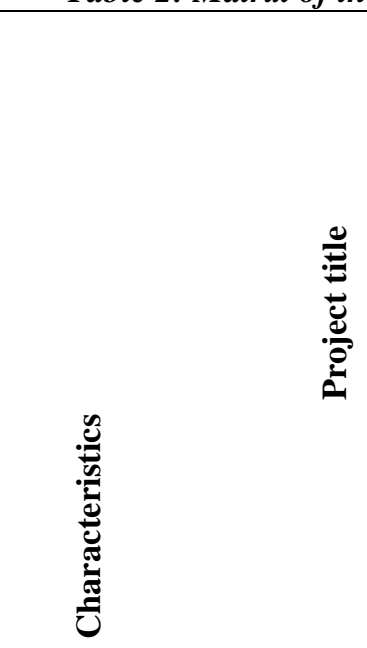 } & \multirow[b]{2}{*}{ 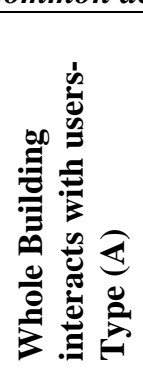 } & \multicolumn{4}{|c|}{ Space/ Surface interacts with users- Type (B) } \\
\hline & & & 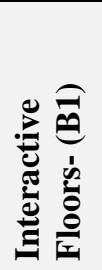 & 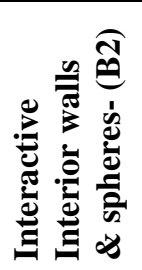 & 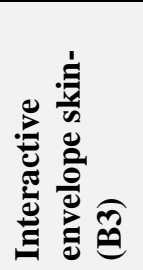 & 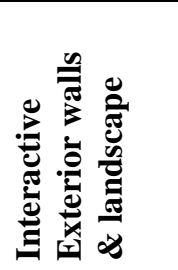 \\
\hline & & ह & 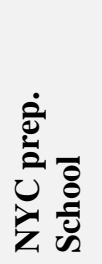 & $\underset{0}{\ddot{B}}$ & 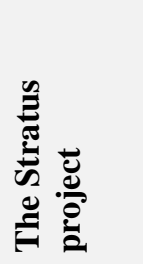 & 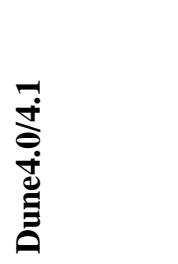 \\
\hline \multirow{3}{*}{ 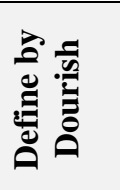 } & Participative/ Agency & $\bullet$ & $\bullet$ & $\bullet$ & - & $\bullet$ \\
\hline & Task Accomplishing & • & & $\bullet$ & & \\
\hline & Practical Action & • & • & • & • & $\bullet$ \\
\hline \multirow{7}{*}{ 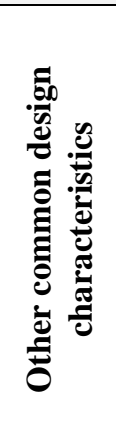 } & Desired Context & & • & $\bullet$ & $\bullet$ & $\bullet$ \\
\hline & Embodied Learning & & • & & & \\
\hline & New Experience & & $\bullet$ & $\bullet$ & $\bullet$ & $\bullet$ \\
\hline & Transformative & $\bullet$ & $\bullet$ & $\bullet$ & • & $\bullet$ \\
\hline & Shared Experience & & $\bullet$ & $\bullet$ & $\bullet$ & \\
\hline & Interface & - & $\bullet$ & $\bullet$ & $\bullet$ & - \\
\hline & Visual Identity & & & $\bullet$ & • & $\bullet$ \\
\hline
\end{tabular}

\section{Conclusions}

Human-centered design is an essential tool in designing a building that meets the human needs. Consequently, Interactive Architecture is considered to be the optimum type of architecture. Many other types have arose that target HCD but Interactive Architecture is believed to be the optimum type, as the Interactive Architecture characteristics are integrated with the HCD methods. To conclude, the following checklist has been achieved in table 3 that illustrates the evaluation of the 39 methods of human-centered design in architecture in the previously discussed examples: Stockholm Central Station, NYC prep. School, BALLS!, The Stratus project, and Dune4.0/4.1. 
Table 3: HCD methods integrated with IA characteristics, (The Author).

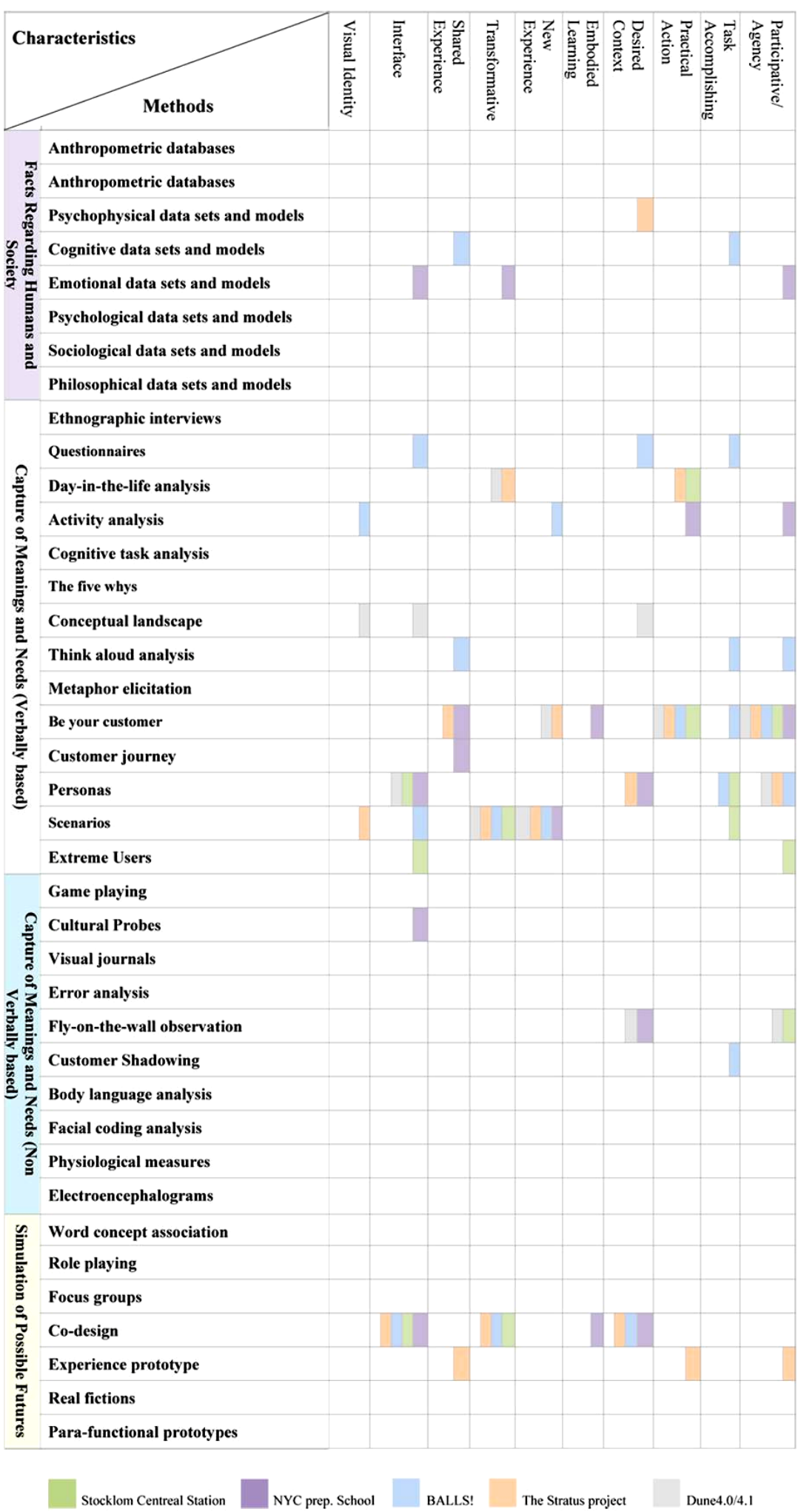

"Human-centered design" is not only considered as a design style, but it's rather a process for designing and developing everything for human who will use them. This could be achieved by understanding humans' needs in designing buildings, communities, services, systems and products. The HCD methods given above give a comprehensive overview of the wide-ranging vision and overarching objectives that a community should keep in mind while undertaking 
any Interactive Architecture design. By knowing the use of each method in the examples it is concluded that in order to reach the optimum new guideline methods of design in architecture for human it must be integrated with interactive applications in buildings. Thus, the specific methods mentioned are the first steps in achieving the optimum guideline for designing an interactive space for humans.

\section{RECOMMENDATIONS}

The following recommendations are a few strategies that may be used to help to promote Interactive Architecture initiatives.

- Develop an overall Vision Plan for the goals and objectives of the HCD process;

- Build public-private partnerships and promote them at a statewide level;

- A broad range of Interactive spaces should be available to bring people interact together and have a new experiences;

- Provide financial incentives and technical assistance to local governments to promote cooperation;

- Use HCD methods in architecture as a new guideline for design to achieve Interactivity;

- Design for human needs and environment to reach comfort and happiness to people;

- Architects must put into consideration people's comfort, stimulating their brains and bodies for learning;

- Use Interactive applications in spaces in order to harvest energy with having a sense of playing;

- Initiate policies to promote protection and conservation of environmental resources.

\section{REFERENCES}

[1] E., S. Greenhouse, ""What is Universal Design," Universal Design," Boston, 2010.

[2] Sam Spurr, "Performative architecture: design strategies for living bodies," Media, \& Performing Arts, Faculty of Arts \& Social Sciences, Univesity of New South Wales, South Wales, Ph.D. T/2007/376, 2007.

[3] Center for Universal Design CUD, "universal design history," NC: North Carolina State University, 2008.

[4] Richard Harper, Tom Rodden, Yvonne Rogers, and Abigail Sellen, Being Human: Human Computer Interaction in 2020. UK, England: Microsoft Research Ltd, 2008.

[5] Martin Maguire, "Methods to support human-centred design," International Journal of Human-Computer Studies, pp. 587-634, 2001.

[6] A. Maslow, A Theory of Human Motivation. New York: Harper, 1943.

[7] A. Maslow and R. Lowery, Toward a Psychology of Being. New York: Wiley and Sons, 1998.

[8] Ting Zhang and Hua Dong, "Human-Centred Design: An Emergent Conceptual Model ," Royal College of Art, London, paper 978-1-905000-80-7, 2008.

[9] International Organization for Standardization IOS, "Human-centred Design Processes for Interactive Systems," London, 1999.

[10]IDEO, The Field Guide to Human-Centered Design , 1st Edition. Canada: IDEO.org, 2015.

[11]L. Gee, Human-centered design guidelines, Learning spaces.: EDUCAUSE, 2006.

[12]W. V. Wells, A. L. Need, and N. Crowell, "Color connotations: A study of color block testing," Journal of Interior Design Education and Research, pp. 5(2), 6, 1979.

[13] M. Portillo and J. H. Dohr, "A study of color planning criteria used by noted designers," Journal of Interior Design, pp. 18(1-2), 17-24., 1993.

[14]Marisha McAuliffe, The Perception of Light: understanding architectural lighting design. London: Oxford Global Press, 2016.

[15]E., S. Greenhouse, "HUMAN-CENTERED DESIGN (also known as universal design, life span design, inclusive design)," Ithaca, NY, 2012.

[16]A. Dunne, Hertzian Tales: Electronic Products, Aesthetic Experience, and Critical Design, 2nd ed. Cambridge, United States of America: MIT Press, 2008. 
[17]J. Giacomin, "What is human centred design?," The Design Journal, vol. 17, no. 4, pp. 606-623, December 2014.

[18]Lucy Bullivant, "Ada: the intelligent room," Architectural design , vol. I, no. 71, pp. 8690., January 2005.

[19]M. Fox and M. Kemp, Interactive architecture (Vol. 1), 1st ed. New York, United states of America: Princeton Architectural Press, 2009.

[20]L. Bullivant, 4dspace: interactive architecture (Architectural Design), 1st ed. New York, United States of America: John Wiley \& Sons, 2005.

[21]M. McCullough, Digital ground: architecture, pervasive computing, and environmental knowing, 1st ed. Cambridge, United States of America: The MIT Press., 2004.

[22]P. Dourish, Where the action is: the foundations of embodied interaction, Paperback edition ed. United States of America: MIT Press, 2004.

[23]C. Day, Places of the Soul: Architecture and Environmental Design as a Healing Art, 2nd ed. Oxford, England: Architectural Press, 2004.

[24]T. Kelly, "Body Heat: Sweden"e s new green energy source," TIME magazine, no. 52, April 2010.

[25]Pavegen. (2014, August) Pavegen Company Web site. [Online]. http://www.pavegen.com/products/ (accessed on January 6, 2015)

[26]R. Glynn. (2014) Interactive Architecture Lab. [Online]. http://www.interactivearchitecture.org/lab-projects/balls (accessed on May 5, 2016)

[27]M. Fox, Interactive Architecture: Adaptive World. Chronicle Books, 1st ed., M. Fox, Ed. New York, United States of America: Princeton Architectural Press, 2016.

[28]Taubman College. (2012) Taubman College Web site. [Online]. https://taubmancollege.umich.edu/research/research-through-making/2011/stratus-project (accessed on February 19, 2014)

[29]2012 RVTR. (2012) RVTR Web site. [Online]. http://rvtr.com/research/research-b/ (accessed on March 13, 2015)

[30]D. Roosegaarde. (2011, September) Studio Roosegaarde Website. [Online]. http://www.studioroosegaarde.nl/project/dune/info/ (accessed on January 8, 2015)

[31]L. Bullivant, "Alice in Technoland. Architectural Design," Architectural Design, vol. 77, no. 4, pp. 6-13, August 2007.

[32]Ruairi Glynn. (2007, January) Interactive architecture Lab. [Online]. http://www.interactivearchitecture.org/dune-40-daan-roosegaarde.html (accessed on November 7, 2014)

[33]S. Spurr, "Performative Architecture- Design Strategies for Living Bodies," Sedney , 2007.

[34]Ting Zhang and Hua Dong, "Human-Centred Design:An Emergent Conceptual Model ," London , 2008. 